$$
\text { S - } 1
$$

\title{
Nanoparticles that Display Short Collagen-Related Peptides. Potent Stimulation of Human Platelet Aggregation by Triple Helical Motifs
}

\author{
Mabel A. Cejas, Cailin Chen, William A. Kinney, ${ }^{*}$ and Bruce E. Maryanoff \\ Contribution from the Vascular Research Team, Johnson \& Johnson Pharmaceutical Research and Development, \\ Spring House, Pennsylvania 19477-0776 USA
}

Supporting Information

4 Pages 
Nonstandard Abbreviations. Fmoc, (9-fluorenyl)methoxycarbonyl; HBTU, 2-[(1Hbenzotriazol-1-yl)-1,1,3,3-tetramethyluronium hexafluorophosphate; HOBT, 1hydroxybenzotriazole; DIEA, $N, N$-diisopropylethylamine; NMP, $N$-methylpyrrolidone; TFA, trifluoroacetic acid; EGTA, glycol-bis(2-aminoethylether)- $N, N, N^{\prime}, N$-tetraacetic acid; PBS, phosphate-buffered saline.

General Experimental. Fmoc-amino acids, HBTU, HOBT, DIEA, NMP and $\mathrm{CH}_{2} \mathrm{Cl}_{2}$ were purchased from Applied Biosystems, Inc. Piperidine was purchased from SigmaAldrich and Fmoc-Gly-Wang resin was from Bachem. The purified peptides were analyzed by MALDI-TOF-MS by M-Scan Inc. Amino acid analyses were performed at the Molecular Structural Facility of University of California at Davis. Aliphatic amine white polystyrene latex nanoparticles $(200 \mathrm{~nm})$ were purchased from Molecular Probes.

Peptide Synthesis. Peptides 1 and 2 were synthesized on an ABI 433A synthesizer using FastMoc chemistry (0.1 mmol scale) and Fmoc-Gly-Wang (0.7 mmol/g, 100-200 mesh). The peptides were cleaved from the resin with 95\% TFA for $2 \mathrm{~h}$. HPLC purification was performed in two Vydac C-18 reverse-phase columns $(25 \times 2.5 \mathrm{~cm})$, using a step gradient of $0-100 \%$ B over 90 min $\left(\mathrm{A}: 0.1 \% \mathrm{TFA} / \mathrm{H}_{2} \mathrm{O} ; \mathrm{B}\right.$ : $80 \% \mathrm{MeCN} / \mathrm{H}_{2} \mathrm{O}$ containing $0.1 \%$ TFA) at a flow rate of $6 \mathrm{~mL} / \mathrm{min}$. The peptides were obtained as a white powder in $36 \%$ (for 1) and 34\% (for 2) overall yield. MALDI-TOF-MS $(\mathrm{M}+\mathrm{Na})^{+}$of 1 calculated for $\mathrm{C}_{64} \mathrm{H}_{92} \mathrm{~N}_{16} \mathrm{O}_{23}$ 1475.7, found 1475.5. MALDI-TOF-MS $(\mathrm{M}+\mathrm{Na})^{+}$of 2, calculated for $\mathrm{C}_{124} \mathrm{H}_{177} \mathrm{~N}_{31} \mathrm{O}_{43}$ 2811.3, found 2812.2. Peptide content for $\mathbf{1}$ and $\mathbf{2}$ were $91 \%$ and $94 \%$ respectively.

Circular Dichroism (CD) Spectroscopy. Peptide solutions $(0.25 \mathrm{mM}$ in water) were stored at $4{ }^{\circ} \mathrm{C}$ for $24 \mathrm{~h}$ for triple helix formation. Concentrations were determined by amino acid analysis. CD spectra were measured at $25^{\circ} \mathrm{C}$ on a Jasco J-710 instrument using $0.1-\mathrm{cm}$ path-length cells (signal averaging 10 scans at a scan speed of $100 \mathrm{~nm} / \mathrm{min}$ ).

Figure S1. CD data of 1 (black) and $\mathbf{2}$ (red) in water.

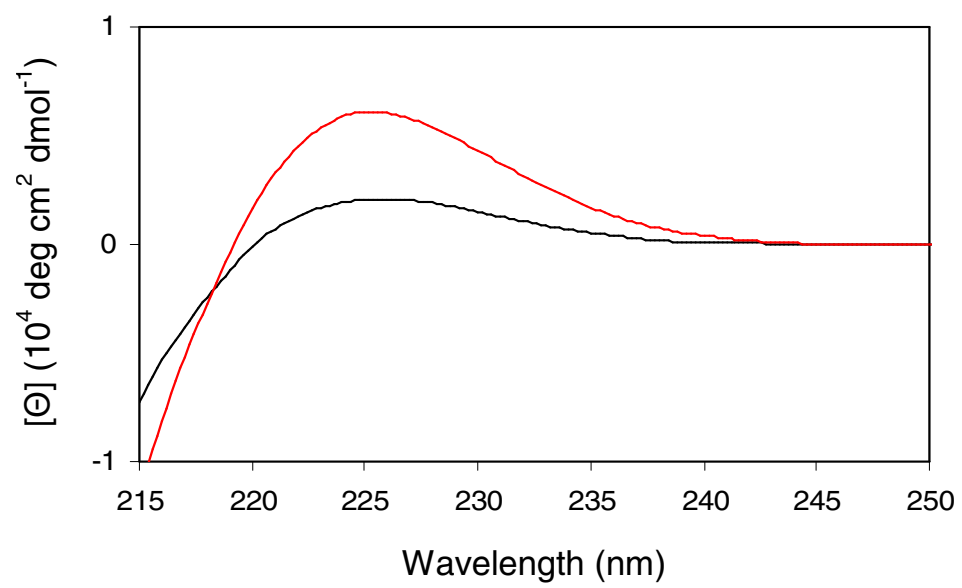


General Procedure to Functionalize Nanoparticles. Polystyrene latex nanoparticles (1 $\mathrm{mL}, 19 \mathrm{mg}$ of nanoparticles, $5.2 \mu \mathrm{mol}$ of amino groups) were centrifuged at $12000 \mathrm{rpm}$ for $30 \mathrm{~min}$ and resuspended in 2-morpholinoethanesulfonic acid (MES) buffer pH 6 (1 $\mathrm{mL})$. The peptide (10 $\mathrm{mol}, 2$ molar excess), dissolved in MES buffer $\mathrm{pH} 6(1 \mathrm{~mL})$, and 1-ethyl 3-(3-dimethylaminopropyl)carbodiimide $\mathrm{HCl}$ (20 molar excess) were added to the nanoparticles and incubated with gentle mixing at room temperature for $12 \mathrm{~h}$. The suspension was centrifuged and the excess of reagents was removed by washing the nanoparticles repeatedly (3 washing/centrifugation cycles) with PBS buffer $\mathrm{pH} 7$. The functionalized nanoparticles were suspended in PBS for the platelet aggregation studies. The degree of functionalization was determined by measuring the amount of peptide that was cleaved off the nanoparticles following acid hydrolysis. Amino acid analysis revealed that a $10 \%$ of amino groups (molar basis) on the surface of the nanoparticles were bound to the peptides. This calculation assumes $100 \%$ recovery of nanoparticles during the processing steps.

Dynamic Light Scattering (DLS). DLS measurements were recorded on a Malvern Zetasizer Zen 1600 instrument equipped with a 633-nm laser (He-Ne $4.0 \mathrm{~mW}$ ) and backscatter detection at $173^{\circ}$. Modified nanoparticles and reference suspended in water were measured in a $1-\mathrm{cm}$ plastic cuvette.

Figure S2. DLS measurements of nanoparticles before (blue) and after functionalization with peptides $\mathbf{1}$ (green) and $\mathbf{2}$ (red).

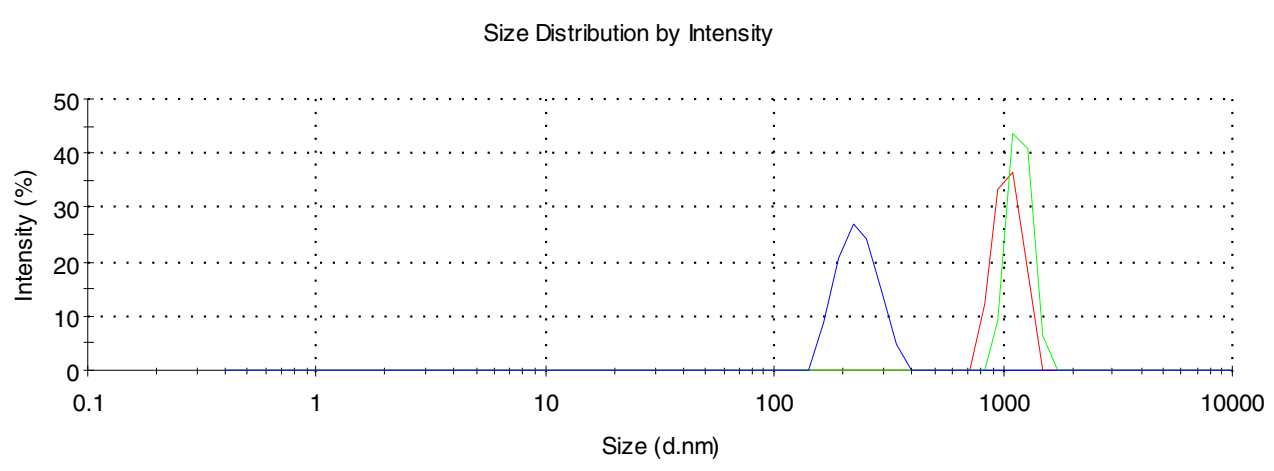

Environmental Scanning Electron Microscopy (ESEM). ESEM images were taken at the University of Miami with a Philips XL30 ESEM-FEG environmental scanning electron microscope. The silicon substrates were mounted on a spin coater and rotated at $3500 \mathrm{rpm}$, a few drops of solution of modified nanoparticles or reference were deposited approximately in the center of the rotating substrates. Images were taken at $5 \mathrm{keV}$. 
Platelet Aggregation. Platelet-rich plasma (PRP) concentrate prepared from a healthy volunteer was purchased from Biological Specialties, Inc. (Colmar, PA). PRP was centrifuged at $730 \mathrm{x} g$ for $15 \mathrm{~min}$. The platelet pellet was washed twice in CGS buffer (13 $\mathrm{mM}$ sodium citrate, $30 \mathrm{mM}$ glucose, $120 \mathrm{mM} \mathrm{NaCl}, \mathrm{pH}$ 6.5) containing $1 \mathrm{U} / \mathrm{mL}$ apyrase (grade V, Sigma, St. Louis, MO) and $1 \mathrm{mM}$ of EGTA and resuspended in Tyrode's buffer (140 mM NaCl, $2.7 \mathrm{mM} \mathrm{KCl,} 12 \mathrm{mM} \mathrm{NaHCO} 3,0.76 \mathrm{mM} \mathrm{Na} 2 \mathrm{HPO}_{4}, 5.5 \mathrm{mM}$ dextrose, $5.0 \mathrm{mM}$ Hepes, $0.2 \% \mathrm{BSA}, \mathrm{pH} 7.4$ ). The platelets were diluted to $3 \times 10^{8}$ platelets $/ \mathrm{mL}$ and kept $>45 \mathrm{~min}$ at $37{ }^{\circ} \mathrm{C}$ before use. $100 \mu \mathrm{L}$ of washed platelets, $2 \mathrm{mM} \mathrm{CaCl}_{2}$ and 2.5 $\mathrm{mM}$ of fibrinogen were added to a 96-well microtiter plate. Platelet aggregation was initiated by the addition of serial concentrations of native collagen (equine type I; 92\% identity with human collagen sequence; Chrono-log Corp., Havertown, PA), peptides, unmodified nanoparticles (reference), or peptide coated nanoparticles. Buffer was added to one set of control wells. The assay plate was stirred constantly and intermittently placed in a microplate reader (Softmax, Molecular Devices, Menlo Park, CA) to read optical density $(650 \mathrm{~nm})$ at 0 and 5 min after the addition of the compound solutions. Aggregation was calculated as the decrease in optical density between the time 0- and 5min measurements and expressed as \% of aggregation.

Table S1. Results for platelet aggregation studies.

\begin{tabular}{|c|c|}
\hline Cmpd & $\mathrm{EC}_{50} \pm \mathrm{SEM}(\mu \mathrm{g} / \mathrm{mL})$ \\
\hline Type I Collagen & $0.40 \pm 0.06$ \\
\hline Nanoparticle-31 mer A & $0.82 \pm 0.06$ \\
\hline Nanoparticle-31 mer B & $0.55 \pm 0.05$ \\
\hline Nanoparticle-31 mer C & $0.47 \pm 0.01$ \\
\hline
\end{tabular}

